\title{
CULTURE-BASED EDUCATION TO FACE DISRUPTION ERA
}

\section{Siti Irene Astuti Dwiningrum}

Universitas Negeri Yogyakarta

siti_ireneastuti@uny.ac.id

Article History

accepted 30/09/2018

approved12/10/2018

published 20/10/2018

\section{Keywords}

disruption, mindset, education, culture

\begin{abstract}
Disruption becomes a social phenomenon that occurs in society in the industrial revolution 4.0 era. However, the educational system in Indonesia has yet to reach education 4.0 standards, which causes more complexity in education-related problems in Indonesia. Moreover, the inequality in education quality and standards has become a tough challenge in building educational system in this era of disruption. Here, the culture-based education to face the challenge of the disruption era can be designed by integrating character education and multicultural education to develop four competencies of students in the education 4.0 era: critical thinking, communication, collaboration, creativity, and innovation. Furthermore, in the proposed education system, teachers must be able to change the fixed-mindset to growth-mindset as a capital to change the paradigm of education to successfully adapt to the era of digitalization and the internet of thing. This is supported by the characteristics that must be possessed by teachers in this era: creative \& innovative, able to conduct multiliteracy pegagogical method, high personal quality, optimal competence, professional, resilient, never give up attitude, honest, discipline, high tolerance, and self confidence. With those characteristics teachers will play a greater role in educating students who are ready to face the disruption era, and making disruption as the future and opportunity to innovate and improve the quality of education.
\end{abstract}

Social, Humanities, and Education Studies (SHEs): Conference Series https://jurnal.uns.ac.id/shes 


\section{PENDAHULUAN}

Indonesia berhadapan dengan era perkembangan Massive Open Online Courses (MOOCs) yang dikatakan melibas apa saja yang berada di depannya (avalanche)(Dhakidae, 2017) di era abad ke-21. Fenomena disruption terjadi secara meluas, mulai dari pemerintahan,ekonomi, hukum, politik, sampai penataan kota, konstruksi, pelayanan kesehatan, pendidikan, kompetisi bisnis dan juga hubunganhubungan sosial (Kasali, 2017). Disruption Education menjadi fenomena sosial di era global. Sebagaimana dijelaskan oleh Yoga (2017, 2018)bahwa fenomena sosialterkaitDisruption Education terus terjadi pada abad 21. Ada empat aspek yang terkaitDisruption Education.Pertama,terkait dengan Student (Generasi NeoMilennials)yaknigenerasi yang langsungbegitu lahir ke dunia sehingga menciptakan "generasi gap", dengan generasi yang sebelumnya.Kedua, Parent (Hyper-Demanding) yakni adanyapeningkatanjumlah "kelas-menengah",yang menyebabkan meningkatnya kebutuhan, termasuk untuk kebutuhandalam pendidikan sehingga meningkatkan homeschooling.Ketiga,Technology(Disruptive Technologies)yakni perkembangan teknologi yang sangat cepat sehingga mengubah cara/metode belajar secara fundamental. Keempat, Skills (Irrelevan skills), yang diperoleh di sekolah (menghafal, multi-choice, dll) "tidak sesuai" dengan keterampilan yang dibutuhkan(kreatif, inovatif, dII). Realitas sosial tersebut menguatkan tantangan pembangunan pendidikan di Indonesia. Di sisi lain, dehumanisasi dalam pendidikan terus terjadi dalam era globalisasi yang menyebabkan krisis karakter bangsa menjadi fenomena sosial yang terus terjadi dalam kehidupan masyarakat Indonesia (Dwiningrum, 2013).Demikian halnya, devaluasi pendidikan menjadi fakta sosial pada kehidupan masyarakat dunia yang sulit untuk dihindari (Dwiningrum 2017).

Tantangan pendidikan pembangunan di abad ke-21 sangat komplek, karena ada dua prinsip yang harus direalisasikan yakni kualitas dan kesetaraan. Setiap negara berusaha untuk menerapkan sistem pendidikan yang dapat menerapkan dua prinsip tersebut.Namun demikian, hasilnya belum optimal, misalnya negara Jerman mencetak siswa elite, tetapi belum unggul dibandingkan Firlandia yang mengejar kualitas dan kesetaraan. Menurut Sahlberg bahwa Firlandia "a model of a modern, publicly financed education system with widespread equity, good quality, large participation-all of this at reasonable cost", partly because of the way the strong social support for children and families that enable all children to come to school ready to learn, without the challenges that many experiences in less well-supported contexts(Hammond, 2017, p. 32). Korea Selatan yang mencetak sekolah eliteternyata belum berhasil.Sebaliknya, Italia, Spanyol, dan Meksiko mengejar kesetaraan namun demikian belum diikuti dengan kualitas. Berbeda dengan Singapura yang terus mengembangkan sistem pendidikan yang responsif dan proaktif terhadap tuntutan pendidikan abad 21. Menurut $\mathrm{Ng}(2017$, pp. 63-64), in education system, meritocracy is generally translate into givingpriority in school choices or allocating higher level of education resources to those who are with merit. The Singapuraeducation system is highly merocratic and competitive. Student compete for a place in their schoolsbased in their school of choice based on merit. Schoos competeto attract good student. Melalui sistem pendidikan yang kompetitif, pemerintah memberikan kesempatan sesuai dengan kemampuan siswa, tanpa mempedulikan perbedaan agama, ras, bahasa, agama ataupun latar belakang sosial ekonomi. Namun demikian, sistem meritokrasi menghadapi paradox, sebagaimana dijelaskan oleh $\mathrm{Ng}$ (2017, p. 61), bahwa akan terjadi selfish meritocracy, maka sistempendidikan mengembangkancompassionate meritocracycan help us build a resilient an inclusive society.Dari beberapa contoh tersebut, dapat disimpulkan bahwa pembangunan pendidikan dinilai berhasil jika minimal dapat menerapkan dua prinsip tersebut yakni meningkatkan kualitas dan kesetaraan secara bersamaan. Bagaimana dengan hasil pendidikan di 
Indonesia?Jawaban atas pertanyaan tersebut tidaklah mudah,karena sistem pendidikan seharusnya menjamin bahwa pendidikan yang berkualitas untuk semua orang.

Ketimpangan mutu yang bersumber dari kualitas dan kesetaraan masih menjadi fenomena sosial di Indonesia. Salah satunya adalah masalah putus sekolah yang masih terjadi pada semua jenjang pendidikan dan terjadi di seluruh wilayah di Indonesia yang masih ditemukan pada setiap jenjang pendidikan dan di seluruh wilayah Indonesia (data profil angka putus sekolah seluruh wilayah Indonesia,2016). Realitasanak putus sekolah bukan sekedar masalah akademik, akan tetapi sumber persoalannya cenderung nonakademis yang membutuhkan penanganan yang komprehensif, karena pendidikanadalah fondasi yang dibutuhkan untuk mencapai kemajuan bangsa yang kompetitifdalammenghadapi tantangan global. Realisasi pemerintah Indonesia semenjak tahun 1984 yang secara formal telah mengupayakan pemerataan pendidikan sekolah dasar, dilanjutkan dengan wajib belajar pendidikan sembilan tahun mulai tahun 1994, seharusnya dikuatkan kembali spiritnya sehingga fenomena anak putus sekolah bisa diatasi dengan tuntas. Sejalan dengan UU Nomor 20 Tahun 2003 tentang Sistem Pendidikan Nasional, pasal 5 ayat (1) menyatakan bahwa "Setiap warga negara mempunyai hak yang sama untuk memperoleh pendidikan yang bermutu", dan pasal 11, ayat (1) menyatakan "Pemerintah dan Pemerintah Daerah wajib memberikan layanan dan kemudahan, serta menjamin terselenggaranya pendidikan yang bermutu bagi setiap warga negara tanpa diskriminasi". UUD 1945 mengamanahkan bahwa setiap warga negara berhak mendapatkan pendidikan untuk meningkatkan kualitas dan kesejahteraan hidupnya. Pembangunan pendidikan merupakan salah satu prioritas utama dalam agenda pembangunan nasional karena perannya yang signifikan dalam mencapai kemajuan di berbagai bidang kehidupan: sosial, ekonomi, politik, dan budaya. Prinsip kualitas dan kesetaraan secara formalsudah memiliki landasan hukum dalam mengatur sistem pendidikan di Indonesia. Oleh karena itu, pemerintah Indonesia masih perlu memikirkan cara yang strategis dan komprehensif dalam mengatasi masalah putus sekolah di era disrupsi.

Masalah anak putus sekolah yang masih ditemukan di Indonesia membuktikan bahwa kebijakan pendidikan belum berhasil mengatasi secara struktural. Hal iniakan berdampak pada kualitas hidup masyarakat secara luas.Secara personal akan berdampak belum optimalnya individu dalam mengembangkan potensi dan hak untuk hidup yang berkualitas. Zamroni (2017)menyatakan bahwa ketimpangan pendidikan tidak bisa dilepaskan dari adanya ketimpangan sosial yang akan saling memperkuat yang memiliki self supporting prophercy sehingga ketimpangan tersebut berkembang semakin besar.Artinya, mengatasi masalah ketimpangan mutu membutuhkan perubahan struktur sosial masyarakat yang kondusif secara sosial-ekonomi bagi perbaikan mutu pendidikan. Oleh karena itu, pembangunan pendidikan Indonesia semakin berat dengan fenomena disrupsi yang terus terjadi pada abad ke-21. Pada makalah akan dibahas dua hal pokok yakni 1) bagaimanapendidikan berbasis budaya diterapkan di sekolah ?; 2) bagaimana peran guru pada abad ke-21?.

\section{PEMBAHASAN}

\section{Pendidikan Dalam Perspektif Teori}

Ketimpangan mutu pendidikan dalam perspektif sosiologis dapat dianalisis dari berbagai teori. Dari perspektif teori fungsionalis structural yang menggambarkan konsekuensi-konsekuensi disfungsional untuk suatu sistem sosial, Ritzer (2012, pp. 429-435) membuktikan bahwa sekolah sebagai salah satu lembaga pendidikan belum menjalankan fungsi sosialnya secara optimal. Sekolah yang seharusnya mampu 
menjadi media sosialiasi yang menghasilkan siswa yang berkembang potensi secara optimal dan menjadi manusia yang berkarakter belum maksimal dilakukan oleh semua sekolah. Sekolah sebagai sistem sosial yang baik sebagaimana dijelaskan oleh John Goodlad belum mewujudkan tujuan sosial-tujuan sekolah secara optimal (Dwiningrum, 2016b, pp. 70-78). Dalam perspektif ini lah problem pendidikan menghadapi masalah yang struktural yang tidak mudah untuk diurai dalam era disrupsi yang membutuhkan daya adaptasi sosial yang memiliki fleksiblitas sosial.

Sekolah dari perspektif teorikonflik yang menekankan pada konsep stratifikasi sosial, dengan adanya kelas sosial (Ritzer, 2012, pp. 4604-462), maka terjadinyaketimpangan mutu pendidikan akan menciptakan kesenjangan sosial yang semakin melebar. Praktik kapitalisasi pendidikan mendorong ketimpangan mutu pendidikan terjadi dalam semua level pendidikan. Sekolah membatasi kesempatan untuk mendapatkan pendidikan yang lebih baik dan lebih tinggi kepada sebagian besar masyarakat. Fakta ini diperkuat dengan masih terbatasnya kesempatan warga masyarakat untuk mendapatkan pendidikan ke level yang lebih tinggi khususnya studi di perguruan tinggi masih belum sampai mencapai $10 \%$ dari jumlah penduduk Indonesia. Struktur masyarakat memberikan kontribusi pada disparitas sosial yang semakin kuat terjadinya ketimpangan mutu di Indonesia. Jika dikaitkan dengan era disrupsi, dapat diasumsikan bahwa pembangunan pendidikan kan menghadapi konflik kepentingan yang semakin kuat, pada hal dalam era disrupsi konflik pentingan dapat direduksi jika budaya memiliki power untuk membangun intepretasi baru dalam kehidupan masyarat, sehingga konflik seharusnya dapat direduksi.

Disisi lain, dalam perspektif teoriinteraksionisme simbolik yang menekankan pada konsep sosialisiasi sebagai proses yang dinamis yang memungkin seseorang untuk mengembangkan kemampuan berpikir dengan belajar melalui interaksi dengan simbol-simbol (Ritzer,2012, pp. 625-629), maka ketimpangan mutu terjadi karena dalam praktik pembelajaran di sekolah masih belum semua sekolah mampu membangun simbol-simbol yang menguatkan perbaikan mutu menjadi kesadaran dan kebutuhan semua unsur yang terlibat dalam proses pembelajaran di sekolah. Peran guru masih variatif dalam mengajarkan pengetahuan yang dibutuhkan oleh siwa. Guru masih terjebak dengan mengajarkan simbol-simbol pengetahuan yang bersifat transfer of knowledge. Guru dalam mengajarkan di kelas terjebak dengan knowing bukan being.Sebagai dampaknya siswa menjadi belum terbentuk menjadi pribadi yang berkarakter, pribadi yang berprestasi, dan pribadi yang resilien. Di sisi lain, kemampuan guru yang ditentukan oleh kompetensi masih beragam antarsekolah sehingga profesionalisme guru juga berbeda kualitasnya, hasil dan prestasi antarsekolah cenderung berbeda. Hal tersebut terjadi, karena guru belum mampu mengembangkan secara optimal kompetesi yang harus dimilikinya seperti halnya kompetensi akademi, kompetensi idiologik, kompetensi pedagogik, kompetensi personal, kompetensi sosial, kompetensi kultural, kompetensi spiritual, komptensi kemanusiaan, dan kompetensi antisipasional (Siswoyo, 2017, p. 11). Dalam era disrupsi, maka pemahaman simbol-simbol dalam proses pendidikan di sekolah dapat dikuatkan lebih sistemik sehingga siswa dapat merespon makna simbol sesuai dengan perkembangan ilmu pengetahuan yang tidak terbatas. Bahkan dalam kontek pendidikan 4.0 dan era revolusi 4.0 yang sudah bergerak pendidikan pada berbasis IT, maka aktivitas membangun interpretasi yang sama menjadi dialog budaya.

Pendekatan sosial-budaya, dikaitkan dengan adanya perbedaan latar belakang sosial-budaya bukan menjadi arena konflik dalam proses pembangunan pendidikan, tetapi menjadi modal sosial dan modal budaya yang mampu menggerakkan semua unsur masyarakat untuk peduli dan terlibat dalam proses pendidikan.Demikian halnya, dengan pendekatan budaya, masalah pembangunan pendidikan harus dilakukan dengan pendekatan budaya agar penguatan culture identity di tengah arus globalisasi dan budaya global yang mereduksi kearifan lokal 
sebagai modal budaya tetap terjaga eksistensi bangsa Indonesia sebagai negara yang berbudaya dan bermartabat. Oleh karena itu, proses pembangunan pendidikan yang bersifat parsial akan menyebabkan berbagai masalah sosialyang semakin komplek yang seharusnya dapat dihindari dalam proses pembangunan pendidikan. Pendidikan perlu untuk menguatkan pengetahuan tentang perspektif global sehingga kemandirian bangsa tetap kuat dalam tantangan global. Pendidikan berperan dalam mendukung pembangunan nasional yang mampu mencetak generasi bangsa yang berkualitas dan berkarakter. Perubahan global dengan liberalisasi pendidikan menuntut lembaga pendidikan untuk mampu menghasilkan kualitas peserta didik yang dapat bersaing secara kompetitif agar dapat diterima pasar. Sebagai konsekuensinya lembaga pendidikan menjadi lebih ke arahknowledge based economyinstitution. Oleh karena itu, pendidikan harus tetap mengacu pada kekuatan dialog budaya, sebagaimana dijelaksan oleh Gal (2005 dalam Baker , p. 274) dalam tulisannya Global Perspective For Teacher Education tentang pentingnya cross-cultural dialogs helps teachers develops an international understanding of contemporary word event, specially by demonstrating how culture and context impact educational values, decisions, public policies, and practise. Local knowledge and a commitment to culturally traditional ways of interacting and communicating values can enhance, rather than detract form academic achievement and developing global prespectives.

\section{Disrupsi pada Pendidikan abad ke-21}

Dialog budaya menjadi aspek yang penting dibangun pada era pendidikan abad ke-21. Hal ini dikaitkan dengan tuntutan pendidikan di abad ke-21 yang menekankan pada kesiapan dalam menghadapi revolusi industry 4.0 yang menekankan pada The future of education: is therefore a new vision for learning, starting right now; more important to know why you need something, a knowledge or skill, and then where to find it - rather than cramming your head full ... don't try to learn everything; built around each individual, their personal choice of where and how to learn, and tracking of performance through data-based customisation ... whatever sits you;learning together and from each other - peer to peer learning will dominate, teachers more as facilitators, of communities built around shared learning and aspiration (Fisk, 2018). Bagi Indonesia, pembangunan pendidikan yang mengacu pada prinsip tersebut masih berat, karena proses pembangunan pendidikan masih pada masalah mendasar yakni masalah mutu.

Masalah pendidikan di Indonesia sangat komplek karena tidak terbatas pada masalah mutu akan tetapi juga tantangan yang sangat berat dalam era diserupsi. Masalah pertama,ketimpangan mutu di Indonesia bersifat struktural, karena kesenjangan mutu terjadi pada seluruh jenjang pendidikan dan masih ditemukan pada seluruh keadaan daerah di Indonesia. Demikian halnya, kinerja sosial sebagai penentu kualitas sekolah belum sama antar sekolah, sehingga hasil dan prestasi sekolah akan berbeda (Jencks dalam Hurn 1993). Dalam artikel Do Schools make a differences membuktikan bahwa sekolah memiliki kontribusi munculnya perbedaan kinerja sekolah, kinerja siswa dan ketidaksetaraan. Masih adanya perbedaan IQ dan motivasi siswa secara akumulatif akan mempengaruhi kinerja sekolah (Hurn, 1993). Padahal, pendidikan merupakan hak yang harus didapatkan oleh seluruh rakyat Indonesia bukan kelompok atau bahkan kalangan tertentu yang dapat menikmati pendidikan dengan hasil yang berkualitas. Pembangunan pendidikan merupakan salah satu prioritas utama dalam agenda pembangunan nasional, karena perannya yang signifikan dalam mencapai kemajuan di berbagai bidang kehidupan: sosial, ekonomi, politik dan budaya. Bagaimana pendekatan struktur untuk mengatasi masalah mutu dalam tantangan pendidikan di abad 21?. Ketimpangan mutu pendidikan bersifat kultural bersumber dari masih adanya perbedaan persepsi masyarakat tentang pentingnya memperjuangkan hak pendidikan dan bersekolah, masih adanya 
perbedaan prestasi belajar siswa.Menurut Zamroni(2017, pp. 7-8) bahwa ketimpangan pendidikan dan sosial akan menimbulkan persepsi bagi warga masyarakatnya yang pada giliran berikutnya akan mempengaruhi sikap dan perilaku warga masyarakat sebagai individu. Dalam konteks inilah, motivasi anak untuk sekolah tidak dapat dipisahkan dengan kondisi sosial-budaya dan ekonomi keluarga. Bagaimana menguatkan eksistensi mereka dalam tuntutan pendidikan yang secara transformatif terus bergerak untuk dapat memenuhi kriteria pendidikan 4.0 di abad 21 yang menekankan pada Education 4.0: Empowering education to produce innovation, sedangkan posisi pendidikan di Indonesia masih berproses dari education 1 ke 3 . Arti education 1.0: centuries of experience with memorization, Education 2.0: Internetenabled learning, Education 3.0: Consuming \& Producing knowledge (Fisk, 2018). Sementara itu dengan mengacu pada pendapat Jencks, maka fenomena masih adanya culturally deprived dan perdebatan antara cultural differences and cultural deficits menjadi tantangan bagi pembangunan pendidikan di Indonesia (Hurn, 1993, pp.110-136).

Di samping itu, tantangan pendidikan dihadapkan dengan perkembangan masyarakat pada era revolusi industry 4.0 sangat komplek. Untuk menghadapi kompetensi pendidikan pada abad ke-21 guru harus mampu mengembangkankompetensi siwa untuk perbaikan kualitas pendidikan di abad ke-21. Perbaikan kualitas membutuhkan pendekatan komprehensif agar hasilnya lebih optimal., karena itu tidak mungkin dilaksanakan dengan kebijakan one fit for all.Saat ini setiap sekolah sebaiknya memiliki daya adaptasi dan fleksibelitas dalam menghadapi tuntutan dan tantangan perubahan di era abad ke-21, karena pada banyak masalah yang harus dihadapi, salah satunya adalah fenomena disrupsi yang menjadi penghambat bagi perbaikan kualitas pendidikan yang masih sangat komplek.

Masalah kedua, fenomena disrupsi tak dapat dihindarkan dalam era abad21.Khususnya bagi pendidikan disrupsi yang dimaknai sebagai sesuatu yang tercabut dari akarnya karena hasilnya berbagai bentuk inovasi, teknologi, platform. Menurut Clayton M.Christensen yang telah memperkenalkan istilah disruption sejalan dengan muncul dan berkembangnya aplikasi-aplikasi teknologi infomasi dan mengubah bentuk kewirausahaan biasa menjadi startup. Kata ini bergeser dari istilah yang dikenal setelah peran dunia, yaitu "destruction" yang diperkenalkan oleh Schumpeter (Kasali, 2017). Disruption merupakan suatu revolusi yang terjadi saat krisis ekonomi Asia (1997) dan Amerika Serikat (2008), anak-anak muda di seluruh dunia begitu bergairah membangun startup ketimbang mencari pekerjaan. Sebagaimana dijelaskan oleh Rhenald Kasali (2017) yang menggambarkan bahwa generasi muda bukan sekedar berwirausaha, melainkan "mendisrupsi" industri, meremajakan, dan membongkar pendekatan-pendekatan lama dengan cara-cara baru.

Disrupsi akanterus terjadi sampai pada titik keseimbangannya. Disrupsi adalah sebuah inovasi yang akan menggatikan seluruh sistem lama dengan cara-cara baru. Disrupsi menggantikan teknologi lama yang serbafisik dengan teknologi digital yang akan menghasilkan sesuatu yang benar-benar baru lebih efisien, lebih bermanfaat (Kasali, 2017:34). Fenomena perubahan yang terjadi disertai perlawanan-perlawanan, pertengkaran aturan, dan adu kencang dalam urusan regulasi. Oleh karena itu, saat ini dibutuhkan pemimpin yang bijaksana, yang mampu berpikir terbuka (Kasali, 2017:163). Dalam konteks inilah, tindakan self disruption lebih penting daripada membiarkan diri teredisrupsi oleh pendatang-pendatang baru. Konsep disruption dibutuhkan agar lebih memahami fenomena-fenomena sosial yang terkait dalam era disrupsi. Kasali (2017:162) menjelaskan beberapa konsep pokok yang terkait dengan disruption adalah suatu proses yang tidak terjadi seketika, tetapi dimulai dari ide, riset atau eksperimen, kemudian terjadi proses pembuatan, pengembangan business model. Ketika berhasil, pendatang akan mengembangkan usahanya pada titik pasar terbawah yang diabaikan incumbent, lalu perlahan-lahan menggerus ke atas, ke segmen yang sudah dikuasi 
incumbent. Dengan memasuki pasar dengan business model baru, yang berbeda dengan yang sudah dilakukan pemain-pemain lama, karena itu inovasi business model menjadi penting. Dalam konteks inilah, tidak semua disruption sukses menjadi pelaku disruption atau menghancurkan posisi incumbent yang tak harus selalu berubah menjadi disruptor. Ada banyak strategi yang bisa ditempuh incumbent, termasuk meneruskan sustainable innovation dan membentuk unit yang lain melayani disruptor. Teknologi bukan disruptor, tetapi enabler. Demikian halnya dengan perkembanganIT, alat-alat lain dibutuhkan untuk mendukung keberhasilan. Disruption dapat menyebakan deflasi, harga turun, karena disruptor memulai low cost strategy. Disruption dalam peradaban exponensial telah mengubah dunia tidak lagi bergerak secara linear dan bertahap dalam cara berpikir manusia, tetapi bergerak sangat cepat dan semakin cepat. Sebagaimana dijelaskan oleh Peter $\mathrm{H}$. Diamandis yang menyimpulkan bahwa manusia tidak akan mengalami keterbelengguan pola pikir linear, tetapi menghubungkan framework dengan menerapkan prinsip $6 \mathrm{D}$ sebagai berikut (Kasali, 2017):

Fase

Digitize

Deceptive

Disruptive

Demonetisasi pertemuan internal.

Deskripsi

Melakukan digitalisasi yang menyebabkan manusia lain ingin pelakukan pertukaran dan saling berbagai ide, karena bisa dilakukan dua arah, inovasi bergerak dengan cepat.

Terjadi perubahan pola sosial di beberapa tempat atau perusahaan hanya terjadi di perusahaan tertentu atau dilokalisasi, sehingga tidak akan meyebar pengaruhnya. Ada kencenderungan bertindak lamban yang menyebabkan incumbent yang tetap memakai cara lama dalam merespon masalah yang terjadi.

Teknologi telah melakukan inovasi baru dan menciptakan pasar baru, menggantikan yang lama. Turbulensi terjadi karena terjadinya

Proses pencampakan karya atau peran uang. Kehidupan masyarakat digambarkan yang memperoleh secara gratis, tetapi sekaligus menunjukkan model bisnis yang mengratiskan adalah perusahaan yang memperoleh keuntungan.

Dematerisasi Proses pemusnahan barang atau jasa, dari lama ke yang baru. Sebagai contohnya rol film ke kamera digital yang tidak memerlukan bahan plastik atau cetak kertas.

Demokratisasi Keadaan kehidupan manusia yang segala sesuatu nya menjadu mudah dan murah, sehingga banyak hal semakin tesedia dan terjangkau untuk memenuhi kebutuhan semua orang.

Fenomena di atas membutuhkan perubahan pola pikir masyarakat. Demikian halnya, dengan dunia pendidikan semakin berat dalam menghadapi era disrupsi. Guru harusmengubah pola pikir. Tugas guru di era disrupsi adalah menjadikan siswa yang memiliki karakter yang kreatif dan inovatif agar siswa memiliki daya adaptasi yang tinggi dalam menghadapi zaman yang serba kreatif dan inovatif membutuhkan nilai karakter yang pantang menyerah, jujur, kreatif, inovatif, tenggang rasa, disiplin, resilien dan rasa percaya diri. Rhenald (2016) menjelaskan bagi masyarakat yang merayakan perubahan, disrupsi adalah masa depan. Namun demikian, sebagian masyarakat yang merasa sudah nyaman dengan keadaan sekarang dan takut dengan perubahan, mereka akan berpikir bahwa ini adalah awal kepunahan. Persoalannya, bagi pendidikan mampu berperan dalam era disrupsi sebagai sebuah kesempatan untuk memperbaiki masalah pendidikan di Indonesia.

Bagi bangsa Indonesia, tujuan pembangunan tetap berupaya untuk mempertahankan identitas budaya di tengah arus revolusi industro 4.0 yang 
melibaskan budaya bangsa menjadi budaya global yang semakin sulit untuk direduksi. Saat ini masyarakat semakin dinamis dalam menghadapi dampak dinamika revolusi industri 4.0yang masih berlangsung dalam kehidupan sosial yang membutuhkan kemampuan responsifdan sikap proaktif yang tinggi. Untuk memahami dinamika yang terjadi pada revolusi industri 4.0 dapat mengkaji artikel yang dipaparkan oleh McKinsey \& Company yang memaparkan dalam laporannya berjudul An Incumbent's Guide to Digital Disruption yang memformulasikan empat tahapan posisi di tengah era distruptif teknologi yakni: Tahap pertama, sinyal di tengah kebisingan (signals amidst the noise). Pada tahun 1990, Polygram dicatat sebagai salah satu perusahaan recording terbesar di dunia. Namun, pada 1998 perusahaan ini dijual ketika teknologi MP3 baru saja ditemukan sehingga pemilik masih merasakan puncak kejayaan Polygram pada saat itu dan memperoleh nilai (value) penjualan yang optimal.Contoh lainnya adalah industri surat kabar tradisional yang mengejar oplah dan pemasukan dari pemasangan iklan. Kemunculan internet yang mengancam dimanfaatkan oleh Schibsted, salah satu perusahaan media asal Norwegia yang menggunakan internet untuk mengantisipasi ancaman sekaligus memanfaatkan peluang bisnis.Perusahaan ini melakukan disruptif terhadap bisnis inti mereka melalui media internet yang akhirnya menjadi tulang punggung bisnis mereka pada kemudian hari. Pada tahap ini, perusahaan (incumbent) merespons perkembangan teknologi secara cepat dengan menggeser posisi nyaman dari bisnis inti yang mereka geluti mengikuti tren perkembangan teknologi, preferensi konsumen, regulasi dan pergeseran lingkungan bisnis.Tahap kedua,perubahan lingkungan bisnis tampak lebih jelas (change takes hold). Pada tahap ini perubahan sudah tampak jelas baik secara teknologi maupun dari sisi ekonomis, namun dampaknya pada kinerja keuangan masih relatif tidak signifikan sehingga belum dapat disimpulkan apakah model bisnis baru akan lebih menguntungkan atau sebaliknya dalam jangka panjang. Namun, dampak yang belum signifikan ini ditanggapi secara serius oleh Netflix tahun 2011 ketika menganibal bisnis inti mereka yakni menggeser fokus bisnis dari penyewaan DVD menjadi streaming. Ini merupakan keputusan besar yang berhasil menjaga keberlangsungan perusahaan pada kemudian hari sehingga tidak mengikuti kebangkrutan pesaingnya, Blockbuster.Tahap ketiga, transformasi yang tak terelakkan (the inevitable transformation). Pada tahap ini, model bisnis baru sudah teruji dan terbukti lebih baik dari model bisnis yang lama. Oleh sebab itu, perusahaan incumbent akan mengakselerasi transformasi menuju model bisnis baru. Namun demikian, transformasi pada tahap ini akan lebih berat mengingat perusahaan incumbent relatif sudah besar dan gemuk sehingga tidak selincah dan seadaptif perusahaan-perusahaan pendatang baru (startup company) yang hadir dengan model bisnis baru.

Oleh sebab itu, pada tahap ini perusahaan sudah tertekan pada sisi kinerja keuangan sehingga akan menekan budget bahkan mengurangi beberapa aktivitas bisnis dan fokus hanya pada inti bisnis perusahaan incumbent.Tahap keempat, adaptasi pada keseimbangan baru (adapting to the new normal). Pada tahap ini, perusahaan incumbent sudah tidak memiliki pilihan lain selain menerima dan menyesuaikan pada keseimbangan baru karena fundamental industri telah berubah dan juga perusahaan incumbent tidak lagi menjadi pemain yang dominan. Perusahaan incumbent hanya dapat berupaya untuk tetap bertahan di tengah terpaan kompetisi.Pada tahap inipun para pengambil keputusan di perusahaan incumbent perlu jeli dalam mengambil keputusan seperti halnya Kodak yang keluar lebih cepat dari industry fotografi sehingga tidak mengalami keterperosokan yang semakin dalam. Berangkat dari tahapan-tahapan ini seyogianya masing-masing perusahaan dapat melakukan deteksi dini posisi perusahaan sehingga dapat menetapkan langkah antisipasi yang tepat.Tantangan terberat justru kepada para market leader di mana biasanya merasa superior dan merasa serangan disruptif hanya ditujukan kepada kompetitor minor yang kinerjanya tidak baik. 
Oleh sebab itu, perusahaan incumbent perlu terus bergerak cepat dan lincah mengikuti arah perubahan lingkungan bisnis dalam menyongsong era revolusi industri generasi keempat (Industry 4.0). Reed Hasting, CEO Netflix pernah mengatakan bahwa jarang sekali ditemukan perusahaan mati karena bergerak terlalu cepat, namun sebaliknya yang seringkali ditemukan adalah perusahaan mati karena bergerak terlalu lambat (Andreas Hassim, 2016). Dengan memahami tahapan dalam revolusi 4.0 , dunia pendidikan semakin berat, karena Indonesia saat ini masih bergerak pada pendidikan 2.0 ke pendidikan 3.0 dan masih menghadapi masalah untuk berproses ke pendidikan 4.0. Oleh karena pilihan untuk merancang pendidikan berbasis budaya diharapkan mampu mereduksi masalah di era disrupsi. Persoalannya bagaimana dunia pendidikan mampu merespon perubahan yang akseleratif, sementara proses pendidikan masih belum dinilai responsif terhadap perubahan ? Fenomena disruptif yang terjadi dalam semua aspek kehidupan sosial seharusnya disikapi secara proaktif, sehingga disrupsi yang terjadi tidak menimbulkan masalah sosial, tetapi menjadi dinamisator perubahan sosial ke arah kualitas kehidupan yang lebih baik. Pendekatan budaya dan dialog budaya menjadi salah satu alternatif yang menarik untuk dipertimbangkan dalam menata pendidikan di era disrupsi.

\section{Pendidikan berbasis budaya dalam menghadapi disrupsi}

Manusia adalah "man in culture" membuktikan bahwa setiap manusia tidak bisa lepas dari budaya. Dalam era revolusi 4.0 perdebatan tentang eksistensi budaya menjadi semakin penting, karena budaya global sudah mulai masuk dalam seluruh lini kehidupan manusia dalam dunia. Oleh karena itu, menguatkan pendidikan berbasis budaya dalam era disrupsi menjadi diskusi yang sangat menarik. Bagi kondisi Indonesia pendidikan berbasis budaya menjadi penting, yakni ada beberapa alasan pokok : pertamabudaya mutu masih rendah, kedua,eksistensi budaya lokal sudah mulai tergeser dengan budaya global, ketiga, proses interaksi sosial tergeser dari sistem tradisional ke modern; keempat, komptensi guru sebagian besar belum berbasis budaya IT di era revolusi 4.0.

Pengembangan konsep pendidikan berbasis budaya membutuhkan sinergitas peran sosial. Pendidikan berbasis budayadiperkuat, dipertajam, dan dikembangkan dengan konsep dan praksis berbasis kualitas. Sebagaimana dipaparkan pada awal diksusi bahwa masalah kualitas masih menjadi problem pendidikan di Indonesia. Konsep pendidikan berbasis budaya menekankan pada penguatan nilai-nilai sosial budaya untuk melestarikan dan mengembangkan budaya lokal untuk membangun karakter bangsa. Dalam konteks inilah budaya menjadi basis kegiatan dalam pembelajaran memiliki muatan tentang budaya pada kegiatan intra-kurikuler dan ekstra-kurikuler di sekolah. Proses pembelajaran di sekolah memberikan pengenalan, pengetahuan, pembiasaan dan pembudayaan nilai-nilai budaya sebagai landasan untuk melakukan aktivitas sosial. Di samping itu, lingkungan sekolah yang dibangun budaya sekolahselayaknya disesuaikan dengan kebutuhan siswa untuk semangat belajar di era abad ke-21. Hal yang perlu dipahami bahwa belajar dalam perspektif budaya merupakan proses belajar yang bersifat utuh dan menyeluruh dari keberagaman yang ada dalam suatu komunitas. Oleh karena itu, dalam proses belajar yang dirancang dalam kurikulum nasional ditujukan untuk menghasilkan pola pikir ilmiah sebagai ekspresi perwujudan budaya, demikian halnya dengan kemajuan teknologi dan ilmu pengetahuansebagai cerminan keberhasilan manusia yang berbudaya dan berkarakter. Pendidikan berbasis budaya merupakan strategi penciptaan lingkungan belajar dan perencanaan pembelajaran yang mengintegrasikan pendidikan karakter menjadi fondasi dalam proses pembelajaran di sekolah agar siswa menjadi pribadi yang berkarakter, demikian halnya pendidikan multikultural dibutuhkan untuk membangun perspektif dalam menghadapi era globalisasi.Pendidikan karakter adalah usaha sadar dan terencana untuk mewujudkan suasana serta proses 
pemberdayaan potensi dan pembudayaan peserta didik guna membangun karakter pribadi atau kelompok yang unik baik sebagai warga negara. Pendidikan karakter akan membentuk kepribadian yang mendorong individu dalam bertindak, bersikap, berucapa, dan merespon sesuatu yang terjadi dalam kehidupan sosial (Dwiningrum, 2013).

Pendidikan multikultural diharapkan menjadi kekuatan untuk melakukan transformasi sekolah, dari sekolah yang penuh ketimpangan menuju sekolah yang penuh dengan kesadaran dan keadilan, termasuk tranfromasi kebijakan sekolah, sikap guru, materi pembelajaran, cara-cara evaluasi, bimbingan konseling serta gaya pembelajaran. Implementasi pendidikan yang diselenggarakan secara demokratisdan berkeadilan serta tidak diskriminatif dengan menjunjung tinggi hak azasi manusia, nilai keagamaan, nilai kultural, dan kemajemukan bangsa, akan mewujudkan suatu sekolah dimana semua siswa nyaman dan betah betah di sekolah. Sekolah yang nyaman memudahkan siswa untuk menguatkan cita-cita dan meretas jalan untuk mewujudkannya. Sekolah yang nyaman berarti guru membangun "ruang" baru, "ruang" yang nyaman untuk semua siswa yang berbeda latar belakang untuk mengembangkan potensi dirinya secara optimal. Sekolah yang "nyaman" dan guru yang berkualitas mendorong resilien siswa sehingga siswa akan terus termotivasi belajar sesuai dengan kemampuan dan kapasitas sosialnya dalam tantangan di abad 21 (Dwiningrum, 2017). Sebagimana dijelaskan oleh Panth (2017). the role of the educator becomes much more challenging and more than that of an individual who just teaches to prepare student to pass examination. Instead, he or she is now fasilitator, coach and teacher who devotes his time to the development of a whole spectrum of knowledge, skills, values, and dispotions.Dalam konteks inilah, pendidikan berbasis budaya yang dirancang dengan menciptakan lingkungan belajardan merancang pengalaman belajar yang mengitegrasikan budaya sebagai bagian dari proses belajar di sekolah. Pendidikan berbasis budaya menekankan pada penyadaran bahwa budaya adalah aspek fundamental bagi pendidikan dan cara untuk mengekspresikan atau mengkomunikasikan suatu gagasan dan pengetahuan yang dibutuhkan dalam menghadapi era disrupsi. Hal ini dimaksudkan sebagai bagian penting dalam proses pembelajaran dengan penguatan pada nilai sosial budaya dalam membentuk karakter siswa. Dampak pendidikan yangakan dirasakan oleh siswa lebih bermakna secara kontekstual yang terkait dengan komunitas budaya tertentu, di sisi lain proses belajar lebih menarik, menyenangkan bagi siswa serta menjadikan siswa menjadi pribadi yang berkarakter dalam lingkungan masyarakat multikultur.

Tujuan pendidikan berbasis budaya adalah mengembangkan potensi afektif siswa sebagai pribadi yang berkarakter dan memiliki kemampuan menjadi priadi yang percaya diri,mandiri, kreatif, berwawasan kebangsaan, dengan mengembangkan lingkungan sekolah sebagai lingkungan belajar yang aman, jujur,penuh kreativitas dan persahabatan serta dengan rasapenting dalam menerapkan praksis pendidikan berbasis budaya. Budaya sekolah menentukan daya adaptasi sekolah. Nilai-nilai yang dikembangkan sekolah akan mempengaruhi perilaku warga sekolah.Sebagaimana dijelaskna oleh Coleman yang merekomendasikan bahwa komponen-komponen dalam "value climate" termasuk di dalamnya adalah leadership, staff cooperation, student behaviour, teacher control over school and classroom policy, and teacher moral (Ballantine,1997:19) akan mempengaruhi perilaku di sekolah.

Budaya sekolah diharapkan mampu merespon era disrupsi. Dengan budaya sekolah maka sekolah mampu beradaptasi dengan perubahan sekolah. Budaya yang dikembangkan oleh sekolah sangat ditentukan oleh tujuan mutu. Oleh karena itu, budayadalam perspektif mutu sekolah sebagai eksternalisasi dikuatkan dalam aktivitas di sekolah yang membentuk perilaku yang bermakna dan berkarakter (Dwiningrum, 2017). Budaya sekolah sebagai modal budaya akan membangun habituasi yang diharapkan mambuat membentuk karakter siswa. Dengan modal 
budaya menjadi modal perbaikan mutu sekolah. Modal budaya akan efektif jika seluruh warga sekolah menjadikan "nilai mutu" sebagai spirit dalam perbaikan sekolah. Modal budaya dijelaskan olehBourdieu bahwa modal memiliki definisi yang sangat luas dan mencakup hal-hal material (yang dapat memiliki nilai simbolik) dan berbagai atribut 'yang tak tersentuh', namun memiliki signifikansi secara kultural, misalnya: pretise, status, dan orotitas (yang dirujuk sebagai modal simbolik) serta modal budaya (Harker, 1990: 13-16). Modal budaya dapat mencakup rentangan luas properti, seperti seni, pendidikan, dan bentuk-bentuk bahasa. Modal berperan sebagai sebuah relasi sosial yang terdapat di dalam suatu sistem pertukaraan, dan istilah ini diperluas 'pada segala bentuk barang-baik material maupun simbol, tanpa perbedaan-yang mempresentasikan dirinya sebagai sesuatu yang jarang dan layak untuk dicari dalam sebuah formasi sosial tertentu. Dengan modal budaya, maka pendidikan akan bergerak dinamis dalam merespon setiap perubahan dengan lebih proaktif dan "positive thinking".

Sependapat dengan Cheng (2005) bahwa perubahan paradigma menjadi aspek penting yang harus dikaji agarpembangunan pendidikantidak terjebak dengan fenomena disrupsi yang masuk dalam semua aspek kehidupan manusia. Strategi yang paling efektif dalam membangun pendidikan berbasis budaya pada era abad ke-21 dengan melakukan perubahan paradigma. Pekerjaan yang tidak mudah, karena hal ini membutuhkan perubahan struktural dan kultural yang sinergis. Perubahan paradigma penting untuk direkonstruksi karena efek disrupsi telah mengubah proses sosial semakin akseleratif dalam proses pendidikan. Pemikiran Cheng (2005) menarik untuk didiskusikan, karena perubahan paradigma pendidikan dalam era globalisasi terkait dengan perubahan sistem pendidikan pada aspek "learning" dan "teaching" yang melandasi konsep dasar bagi perubahan sistem pendidikan di era abad ke-21 dinilai lebih responsif dalam menyikapi era digitalisasi. Secara umum perubahan paradigma pendidikan dapat dipaparkan padatabel berikut ini :

Tabel 1. Paradigm Shift in Learning

\begin{tabular}{cc}
\hline New CMI-Triplization Paradigm & Traditional site-Bounded Paradigm \\
\hline Individualized Learning & Reproduced Learning \\
- Student is the Centre of Education & - Student is the Follower of Teacher \\
- Individualized Progams & - Standar Progams \\
- Self-Learning & - Absorting Knowledge \\
- Self-Actualizing Process & - Receiving Process \\
- Focos on How to Learn & - Focus on How to Gain \\
- Self Rewarding & Instituion-Bounded Learning \\
Localized and Glovalized Learning & - Teacher-Based Learning \\
- Multiple Sources of Learning & - Separated Based- Learning \\
- Networked Learning & - Fixed Period and Within \\
- Lifelong and Every where & Institutions \\
- Unilimited Oppotunies. & - Limited Opputunities \\
- Local-Claass Learning & - Site-Bounded Learning. \\
&
\end{tabular}

Perubahan paradigma dirancang aspek "teaching" yang dinilai dapat mengatasi masalah pendidikan di era disrupsi, dapat dijabarkan sebagai berikut.: 
Tabel 2. Paradigm Shift in Teaching

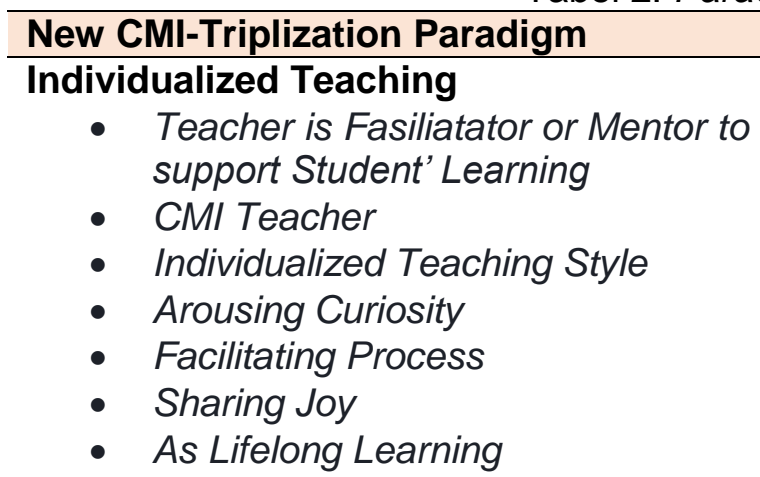

\section{Localized and Glovalized Teaching}

- Multiple Sourcess of teaching

- Networked Taching

- Word-Class Teaching

- Unlimited Opputunities

- Local and International Outlook

- A World-Class and Networked Teacher

\section{Traditional site-Bounded Paradigm} Reproduced Teaching

- Teacher is the Centre of Education

- Partially Comptent Teacher

- Standart Teaching Style

- Transferring Knowledge

- Delivering Process

- Achieving Standards

- As a Practices of Previous Knowledge

Instituion-Bounded Teaching

- Site-Bounde in Teaching

- Separated Teaching

- Bounde Teaching

- Limited Opputunities

- Mainly Institution Experinces

- AsSite-Bounded and Separated Teacher

Perubahan paradigmadi atas dapat dijadikan sebagai proses rekonstruksi sosial dalam sistem pendidikan di era abad ke-21 yang tidak mudah dilakukan jika kebijakan pendidikan tidak diubah dan jika guru tidak siap dalam menghadapi tantangan era disrupsi. Oleh karena itu, guru harus mengembangan inovasi yang terus berlangsung dalam kehidupan sosial. Guru memiliki peran yang sangat strategis untuk menjadi guru-guru yang memiliki kesempatan untuk mengembangkan kreativitas dan inovasi dalam proses pembelajaran di era digital.

\section{Peran Guru pa.da Abad ke-21}

Guru pada abad ke-21 harus mengubah mindset dari fix-mindset ke growth mindset. Oleh karena itu, seorang guru mampu merancang pendidikan dengan pendekatan multiliteracy pedagogical planning dengan mempersiapkan peserta didik untuk memiliki berbagai kompetensi.Pertama, memiliki kompetensi untuk kolaborasi lintas negara, lintas budaya, agama dan bahasa, dan memilki kompetensi diversity dengan baik, pengetahuan, sikap, dan tindakan sehingga bisa berkolaborasi dengan siapa saja di dunia.Kedua,memiliki kompetensi dalam komunikasi global, bisa menggunakan bahasa yang bisa difahami oleh masyarakat dunia, baik komunikasi verbal maupun tulisan, baik dalam aspek reading maupun writing sehingga bisa menjadi bagian penting dalam sebuah perusahaan industri, jasa atau lainnya.Ketiga,menguasai teknologi informasi dengan baik, untuk akses informasi, komunikasi, penyampaian informasi pada publik dan bahkan juga untuk menyimpan data yang diperlukan untuk dibuka setiap setiap saat, movable, dan bisa diakses kapan saja dan di mana saja sehingga sangat membantu dalam proses pengambilan keputusan.Keempat, memiliki kemampuan critical thinkingyang baik, mampumengubah masalah menjadi kesempatan untuk maju, berpikir kreatif inovatif, dan bahkan memiliki kemampuan problem solving yang baik, yang semua ini bisa dikembangkan dengan pelatihan dalam proses pembelajaran atau pelatihan khusus di luar jadwal rutin mata pelajaran yang biasanya berbasis disiplin ilmu pengetahuan (Rosyada, 2017). Bagaimana peran guru untuk mengembangkan proses belajar dengan tetap mengintergasikan nilai-nilai karakter dalam membentuk komptensi siswa? 
Guru berperan menjadi fasilitator dan mediator yang mampu mendorong siswa untuk belajar dan berpikir kritis dalam situasi yang menyenangkan. Guru tidak lagi menjadi sumber dan pusat belajar utama, tetapi lebih berperan sebagai katalisator dalam menghadapi proses belajar yang bersifat akseleratif di era digital. Guru harus mampu menjadi inspirator bagi siswa dalam menggugah rasa keinginan tahuan siswa dalam menghubungkan antara fakta dan perkembangan IPTEK yang semakin cepat. Guru adalah teman berbagi, bercerita dan berkolaborasi untuk mencapai tujuan untuk membentuk kualitas siswa. Oleh karena, guru diharuskan menyiapkan siswa yang memiliki critical thinking, comunication, collaboration, creativity, and innovationyang secara rinci dipaparkan sebagai berikut (Peter Fisk, 2015).

Tabel 3. Pengembangan Kompetensi Siswa abad ke-21

\begin{tabular}{|c|c|}
\hline Kompetensi & Kemampuan yang dikembangkan pada siswa antara lain: \\
\hline $\begin{array}{l}\text { Critical } \\
\text { Thinking }\end{array}$ & $\begin{array}{l}\text { Kemampuan mengembangkan cara berpikir yang menekankan } \\
\text { pada kebenaran pada kebenaraan proses dan prosedur, serta } \\
\text { integritas berfikir yang disandarkan pada teori dan regulasi. } \\
\text { - Kemampuan menggunakan metodologi berfikir yang sainstifik, } \\
\text { berbasis data, teori, regulasi dan konsep, serta analisis obyektif } \\
\text { dengan teknik dan metode yang benar. } \\
\text { - Kemampuan mengembangkan ketrampilan atau strategi kognitif } \\
\text { untuk meningkatkan probabililitas pencapaian outcome. } \\
\text { - Kemampuan menyampaikan argumentasi logis secara efektif, } \\
\text { mampu berfikir sistemik, mampu merumuskan kesimpulan, dan } \\
\text { mampu melakukan problem solving secara efektif. }\end{array}$ \\
\hline Comunication & $\begin{array}{l}\text { Kemampuan menggunakan bahasa yang difahami oleh semua } \\
\text { orang, bisa meyakinkan para penerima, pesannya singkat, jelas } \\
\text { dan sesuai dengan target outcome yang diharapkan, } \\
\text { - Kemampuan menerima semua pesan yang tersampaikan dan } \\
\text { akan mempengaruhi penerima untuk mengikuti atau setidaknya } \\
\text { tidak melakukan penolakan terhadap informasi tersebut. } \\
\text { - Kemampuan memaknai pesan sesuai dengan yang } \\
\text { dimaksudkan oleh pengirim pesan. }\end{array}$ \\
\hline Collaboration & $\begin{array}{l}\text { - Kemampuan melakukan kerjasama dengan membentuk } \\
\text { konsorsium untuk melakukan proyek yang sangat besar, atau } \\
\text { hanya mengembangkan kerjasama dengan saling membantu } \\
\text { sama lain dalam menyelesaikan sebuah pekerjaan. } \\
\text { - Kemampuan mengembangkan ketrampilan yang dimiliki oleh } \\
\text { seseorang untuk mempunyai peran sosial tertentu. Tiga } \\
\text { komponen penting dalam kolaborasi adalah jejaring kerja, } \\
\text { koordinasi dan kerjasama (cooperation). } \\
\text { Kemampuan mengembangkan jejaring dengan sesama mitra } \\
\text { kerja untuk bertukar informasi, dan untuk melakukan kerjasama } \\
\text { yang saling menguntungkan. serta dapat melakukan langkah- } \\
\text { langkah kongkrit untuk mengembangkan kolaborasi untuk } \\
\text { mencapai tujuan dan keuntungan bersama. }\end{array}$ \\
\hline $\begin{array}{l}\text { Creativity and } \\
\text { Innovation }\end{array}$ & $\begin{array}{l}\text { - Kemampuan melahirkan sebuah gagasan, konsep baru untuk } \\
\text { menyelesaikan sebuah masalah, atau kemampuan melahirkan } \\
\text { prototype baru untuk melahirkan sebuah produk baru yang akan } \\
\text { dihasilkan. } \\
\text { - Kemampuan berfikir divergen yang bisa memberikan solusi } \\
\text { berbeda dari yang lain tentang sebuah masalah. } \\
\text { - Kemampuan mengembangkan pengalaman dan bertukar } \\
\text { informasi dengan orang lain. }\end{array}$ \\
\hline
\end{tabular}


- Kemampuan mengembangkan kapasitas dalam berfikir kritis dan memiliki kemampuan analis yang baik.

- Kemampuan melakukan inovasi dengan membuat prototype baru, dan produk baru sebagai alternatif untuk memperbaiki produk yang sudah ada.

- Kemampuan melahirkan sebuah formula baru, dan ada proses implementasi formula tersebut untuk bisa dipakai dalam penyelesaian masalah.

Sumber :Boris, Aberšek (2017). Fisk, P. (2018), Yoga (2018).

Berdasarkan paparan di atas dapat disimpulkan bahwa guru mempunyai tugas yang kompleks. Oleh karena itu, guru di abad ke-21 menghadapi masalah yang sangat berat jika tidak memiliki kompetensi yang cukup. Dalam tantangan yang serba kompetetif, maka guru harus konsistenmenuju tujuan mutu. Hal ini penting disadari oleh guru, karena peningkatan mutu sekolah tidak bersifat instan, tetapi suatu proses dinamis yang harus dijalani dengan sabar, tahap demi tahap, yang terukur dengan arah yang jelas dan pasti. Peningkatan mutu sekolah memerlukan teori, namun implementasinya tidak akan bisa mulus dan semudah teori yang ada, disebabkan oleh peningkatan mutu bersifat dinamis yang amat terkait dengan berbagai faktor atau variabel yang tidak semua dapat dikendalikan oleh sekolah (Zamroni, 2009, p. 28). Oleh karenaitu, dalam konteks pendidikan di abad ke- 21 guru masuk pada era professional , maka "pendidik merupakan tenaga profesional" yang secara hukum sudah diatur oleh UU Nomor 20 Tahun 2003 Pasal 39 ayat 2. Profesional adalah pekerjaan atau kegiatan yang dilakukan oleh seseorang dan menjadi sumber penghasilan kehidupan yang memerlukan keahlian, kemahiran atau kecakapan yang memenuhi standar mutu atau norma tertentu serta memerlukan pendidikan profesi. Oleh karena itu, peran pendidik dalam abad ke-21 membutuhkan profesionalitas yang tinggi. Disamping itu, untuk mengatasi masalah ketimpangan mutu bukan pekerjaanmudah. Sebagaimana dijelaskan oleh Siswoyo (2017, pp. 141-142)bahwa perbaikan mutu pendidikan perlu membangun tiga hal penting yakni capacity building, empowerment, dancritical mass. Capacitybuildingdimaknai memberi kesempatan bagi orang-orang untuk bekerja sama dengan sebuah cara baru sehingga dinamika yang dibangun secara kolektif dalam perbaikan pendidikan berjalan dengan baik. Inti dari capacity building adalah hubungan-hubungan kolegialitas, terkait dengan komunitas, dikursus, dan kepercayaan profesional sangat penting. Dua komponen kunci dari capacity building adalah komunitas belajar profesional dan kapasitas kepemimpinan.Capicity building akan membangun mindset yang kondusif untuk perbaikan pendidikan.Menurut Yoga (2018), perubahan mindset akan efektif untuk perbaikan kualitas pendidikan dari fixed ke growth mindset pada siswa di sekolah. Menurut Day (2014, p. 99) capacity is a power - a habid of mind focuced on enganging in and sustaining the learning of people at all level in the educational system for collective purpose of enhancing student learning in its broadest sense. It's a quality that allow people individually and collectively, routinely to learn from the world around them and to apply this learning to new situations so that they can continue on a path toward their goals in an ever-changing contex.Dalam konteks inilah, penguatan kapasitas personal dan sosial menjadi dua hal penting dalam menghadapi tantangan pendidikan.

Dalam menghadapi era disrupsi dibutuhkan guruberkualitas dan memiliki resiliensi yang kuat. Sebagaimana simpulanbeberapa penelitian bahwa resiliensi sekolah akan menentukan kualitas sekolah, demikian temuanDwiningrum (2017)bahwa keberhasilan sekolah dalam menerapkan berbagai kebijakan baru ditentukan oleh tingkat resiliensi sekolah. Pertanyaannya mengaparesiliensi sekolah penting dibangun oleh sekolah? Banyak hasil penelitian menyimpulkan bahwa prestasi sekolah 
ditentukan oleh resiliensi sekolah. Bahkan Christoper Day dan Qoing Gu dalam bukunya Resilient Teachers, Resilient Schoolssecara khusus membahas tentang pentingnya membangun resiliensi sekolah (Day, 2014, pp. 51-86).Day membahas bahwa persoalan yang kompleks yang terjadi dengan kehidupan guru dan sekolah tidak dapat dipisahkan dengan masalah resiliensi sekolah dan resiliensi guru. Resiliensi dibutuhkan oleh sekolah dalam menghadapi tantangan pendidikan abad 21 . Dengan adanya resiliensi sekolah, sekolah lebih efektif dalam mengatasi berbagai masalah pendidikan dan proaktif dalam merespon perubahan kebijakan maupun perubagan tuntutan masyarakat di era revolusi 4.0. Resiliensi dibutuhkan karena resiliensi adalah bagian dari kehidupan "everyday resilience". Kemampuan untuk menjadi tangguh akan muncul saat seseorang belajar untuk memecahkan masalah, mengembangkan kemampuan sosial, dan kompetensi sosialnya (Day, 2014). Resiliensi sekolah membangkitkan keterpurukan dan penyesuaian terhadap berbagai tuntutan perubahan pendidikan abad- 21. Hal ini terkait dengan adanya kemampuan guru untuk mengembangkan kompetensi akademik sosial dan vokasional (Ririkin \&Hoopman dalam Henderson \& Milstein, 2003, pp. 11-26; Esquivel, Doll,\& OadesSese, 2011, pp. 649-651). Setiap orang mempunyai kemampuan yang berbeda dalam mengembangkan aspek resiliensi. Sekolah berperan untuk mengembangkan resiliensi siswa dan guru yang sangat diperlukan untuk menghadapi berbagai perubahan maupun untuk mitigasi bencana. Guru mempunyai peran langsung dalam mengembangkan resiliensi siswa. Keterlibatan guru dalam peningkatan resiliensi sekolah ternyata ditentukan oleh banyak aspek, seperti halnya kompetensi personal, kompetensi sosial, budaya sekolah, sarana prasarana sekolah (Henderson \& Milstein, 2003; Kiswarday, 2006; Condly, 2006; Poliner \& Benson, 2013).

Resiliensi guru sangat penting dikembangkan karena terkait dengan pengembangan identitas profesionalnya yang sangat dibutuhkan pada tantangan abad ke-21. Di samping itu, guru yang resilien mampu mengubah "disruption" menjadi "opportunity", guru mampu mengembangkan "agility" dan tidak terjebak dengan "rigidity" yang menyebabkan proses belajar menjadi belajar "tanpa makna" di era "intenet of thing". Guruyang resilienakan mudah untuk melakukan kerja yang berkualitas. Gururesilien tidak sulit untuk menerapkanpendidikan di abad ke-21. Guru yang memiliki kompetensi yang cukup dan mampu menerapkan "standart excellent"yang dibutuhkan dalam mengatasi mutu sekolah. Guru yang resilien akan menjadi pribadi yang berkarakter. Di sisi lain, prinsip kesetaraan yang dibutuhkan untuk pendidikan diabad ke-21 dapat dilakukan oleh guru dengan mengembangkan pendidikan multikultural. Guru dapat menerapkan prinsip kesetaraan dalam level di kelas, sebagaimana dijelaskan oleh Zamroni(2017, pp. 19-22)dengan menerapkan pendidikan multikultural dapat dilihat sebagai suatu cara untuk melaksanakan pembelajaran, yang memajukan prinsip kesetaraan seperti, tidak membeda-bedakan perbedaan yang ada, memajukan demokrasi, mengembangkan keterampilan untuk mendalami dan memahami permasalahan kehidupan, melaksanakan inkuiri, mengembangkan critical thinking, senantiasa memanfaatkan perspektif nilai-nilai, dan melaksanakan refleksi diri serta mendorong siswa untuk membawa berbagai aspek budaya mereka ke dalam ruang kelas.

Berdasarkan paparan di atas bahwa pendidikan berbasis budaya dalam era disrupsi secara umum dapat digambarkan sebagai berikut: 
SHEs: Conference Series 1 (2) (2018) 20-38

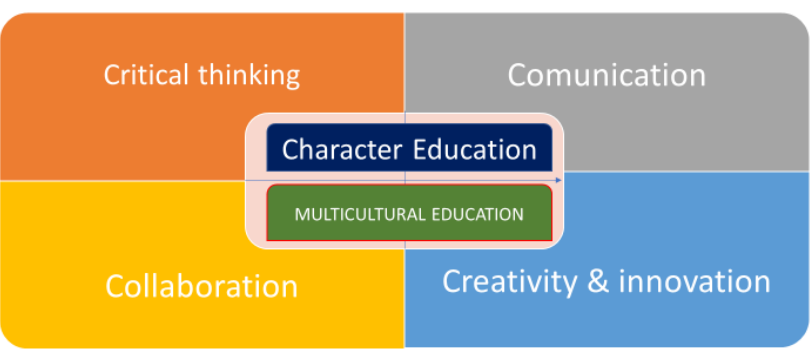

Gambar 1. Pendidikan Berbasis Budaya

Adapun gambaran tentang karakter guru abad ke-21 sebagai berikut:

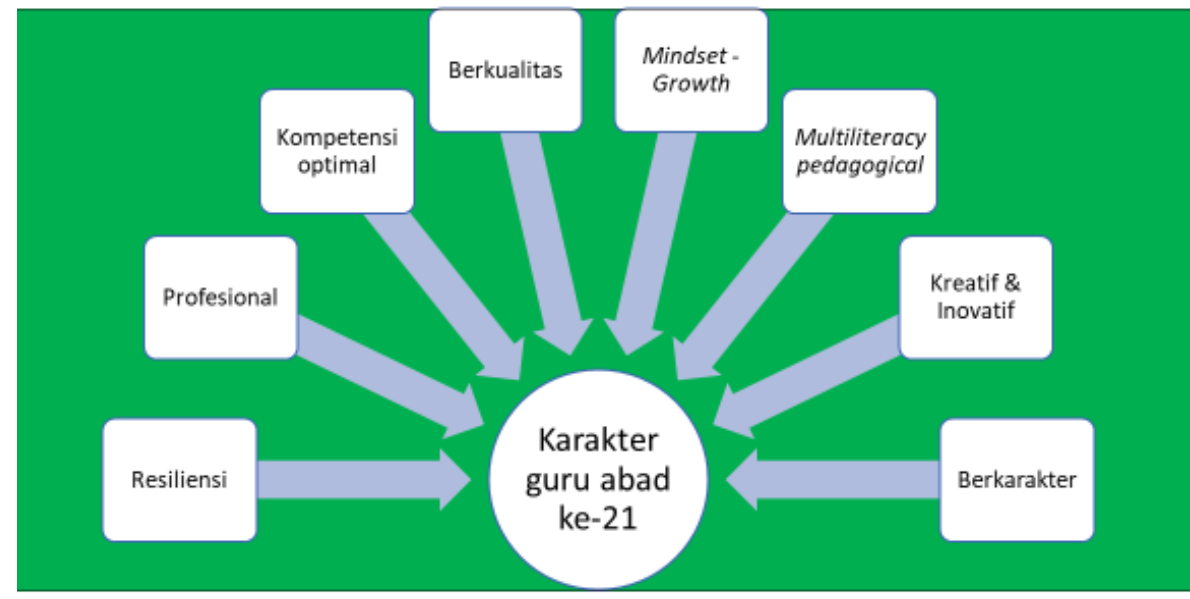

Gambar 2. Ciri Guru Abad 21

Guru yang resilien akan memiliki kualitas kerja dalam menghadapi masalah pendidikan yang sangat kompleks di era revolusi industri 4.0.Era ini menuntut perubahan paradigma pendidikan dengan tindakan antisipatik dengan mengembangkan tiga aspek yakni Data Literation, Technology Literation, dan Human Literation.Oleh karena itu, pendidikan di abad 21 seharusnya menyiapkan generasi yang mampu untuk berpikir inovatif, berkompetensi dalam bidang keilmuan masingmasing, optimum dalam menjalani kehidupan, dan mampu terus menerus belajar. Dalam adopsi teknologi baru kedalam revolusi industri 4.0 abad 21, maka pendidikan dituntut untuk menghasilkan individu yang memilikikemampuan sumber daya manusia untuk melakukan berbagai terobosan, meningkatkan kemampuan untuk menggunakan informasi dari internet dengan optimum, memperluas akses, dan meningkatkan proteksi cyber security.

\section{SIMPULAN}

Fenomena disrupsi terjadi pada masyarat di era revolusi industri 4.0. Problem pendidikan di Indonesia sanga komplek. Ketimpangan kualitas dan kesetaran dalam membangun pendidikan menjadi pekerjaan berat dalam era disrupsi. Perubahan paradigma pendidikan yang dibutuhkan untuk merespon tantangan pendidikan di abad ke 21 agar dapat mempertahankan identitas bangsa pada masa era disrupsi. Pendidikan berbasis budayadirancang untuk mengatasi masalah mutu di Indonesia. Prinsip kualitas dan kesetaraan yang menjadi dasar pokok bagi pembangunan pendidikan harus diatasi secara komprehensif. 
Pendidikan berbasis "knowledge age" yang dibutuhkan oleh pendidikan di abad ke-21 membutuhkan sinergitas peran sosial guru dan siswa. Penguatan pendidikan karakter sangat penting untuk mempertahankan esksistenasi bangsa. Pendidikan multikultural dibutuhkan untuk merespon tuntutan pendidikan di abad ke-21 yang sarat dengan perbedaan dan ketimpangan yang membutuhkan perpektif global .Perubahan paradigma pendidikan perlu direkontruksi dalam sistem pendidikan agar fenomena disrupsi lebih dimaknai sebagai dinamisator bagi perbaikan kualitas pendidikan. Oleh karena, guru yang berkaraketr dan resilien dibutuhkan untuk mengubah pola pikir agar dapat mengembangkan proses pembelajaran lebih efektif dan menyenangkan Dengan pola pikir dari fix-mindset ke growth mindset maka guru dapat lebih kreatif dan inovatif dalam merancang pembelajaran berbasis multiliteracy pedagogical planning. Guru berperan untuk mengembangkan kompetesi 4C (critical thinking, comunication, collaboration, creativity, and innovation) pada siswa secara sistemik. Dengan pendidikan berbasis budaya akan terbentuk pribadi siswa yang berkarakter unggul yang memiliki kemampuan adapatsi dan siap menghadapi masalah pendidikan di era disrupsi.

\section{DAFTAR PUSTAKA}

Baker, David. P, Wiseman, Alexander, W . ed. (2005).Global Trends in Educational Policy. USA: ELVEIER.Jai.

Baron, S., Schuler, T, Field, J. (2000).Socialcapital: Critical perspective. New York: Oxford University.

Boris, Aberšek (2017). Evolution of Competences for New Era Or Education 4.0. .http://cpvuhk.cz/wp-content/uploads/2017/09/Aber\%C5\%A1ek.pdf, diunduh; 5 Oktober 2017

Cheng, Cheong Yin (2005). New Paradigm for Re-engineering Education. Netherlenads: Springer.

Condly, S. J. (2006). Resilience in children: A review of literature with implications for education, Urban Education, 41(3), 211-236. doi: 10.1177/0042085906287902.

Day, C., \& Gu, Q.(2014). Resilient teachers, resilient schools. London \& New York: Routledge Taylor \& Francis Group.

Decker, L.E.,\& Decker, V. A. (2003). Home, school, and community partnerships.Qing, Lanham, Maryland, and Oxford: A Scarecrow Education Book.

Dewantara, K. H. (2013). Pendidikan. Yogyakarta: Majelis Luhur Taman Siswa.

Dewi, N. R.,\& Hendriani, W. (2014) Faktor protektif untuk mencapai resiliensi pada remaja setelah perceraian orangtua.Jurnal Psikologi Kepribadian dan Sosial, 3(3), 37-43. Diunduh dari http://journal.unair.ac.id/downloadfull/JPKS889177aabf9ceefullabstract.pdf.

Dhakidae, D. (2017). Era disrupsi: Peluang dan tantangan pendidikan tinggi Indonesia. Jakarta: Akademi Ilmu Pengetahuan Indonesia.

Dwiningrum, S.I. A. (2013). Ide pengembangan modal sosial dalam perbaikan mutu sekolah dasar di daerah rawan bencana Merapi (Laporan tidak dipublikasikan).LPPM UNY, Yogyakarta.

Dwiningrum, S.I. A. (2016, September 4-8).Building social harmony: Reinforce the foundation of reseaching multicultural education practices in Indonesia and New Zealand. Makalah dipresentasikan pada $41^{\text {th }}$ Pasific Circle Consortium Jepang. JMS Aster Plaza, Hiroshima Japan.

Dwiningrum, S.I.A (2017). "Penguatan Modal Sosial dan Resiliensi Sekolah dalam Mengatasi Ketimpangan Mutu Pendidikan di Abad ke-21". Pidato Pengukuhan Guru Besar . Yogyakarta: Univeritas Negeri Yogyakarta. 
Dwiningrum, S.I.A (2017). Developing school resilience for disaster mitigation: A confirmatory factor analysis". Disaster Prevention and Management: An International Journal, 26(4), 437-451.

Dwiningrum, S.I.A (2018, Januari 8-12). The role of social capital in developing effective and creative schools in primary schools. Makalah dipresentasikan pada ISCEI2018. Nayang Universitas Singapura, Singapura.

Dwiningrum, S.I.A. (2009). Desentralisasi pendidikan dan dinamika sosial(Ringkasan Disertasi). Pascasarjana Sosiologi Universitas Negeri Yogyakarta, Yogyakarta.

Dwiningrum, S.I.A. (2012). Desentralisasi dan partisipasi pendidikan. Yogyakarta: Pustaka Pelajar.

Dwiningrum, S.I.A. (2013). Nation's character education based on the social capital theory. Nation's character education based on the social capital theory. Asian Social Science, Special Issue,9(12).

Dwiningrum, S.I.A. (2014). Modal sosial: Dalam pengembangan pendidikan perspektif teori dan praktik. Yogyakarta: UNYPress.

Dwiningrum, S.I.A. (2014). Schools in education and media hegemony in the perspective of multicultural education. Dalam Proceeding International Conference on Fundamentals and Implementation of Education (ICFIE). Universitas Negeri Yogyakarta, Yogyakarta.

Dwiningrum, S.I.A. (2016). Teori persekolahan. Pascasarjana Universitas Negeri Yogyakarta.

Dwiningrum, S.I.A. (2017, November 7-9). Role of high school on building academic resilience: Comparative study in high school student in Indonesia and Japan. Makalahdipresentasikan pada ${ }^{\text {rd }}$ International Conference on Education. Mudzaffar Hotel, Ayer Keroh, Malaka, Malaysia.

Field, J. (2010). Modal Sosial. Medan : Bina Medai Perintis

Field, J.(2005). Social capital and lifelong learning. Universitas of Bristol : Policy Press.

Fisk, P. (2018). Education $4.0 \ldots$ the future of learning will be dramatically different, in school and throughout life. Diunduh dari: http://www.thegeniusworks.com/2017/01/future-education-young-everyonetaught-together diunduh 20.

Freire, P. (2000). Politik pendidikan: Kebudayaan, kekuasaan, dan pembebasan(Terj.: Agung Prihantoro dan Fuad Arief Furdiyartanto). Yogyakarta: Read dan Pustaka Pelajar.

Glasser,W. (1998). The quality school.Unites State:Harper Perennial.

Hammond, L. D. (2017). Empowered educator. Uni State of America: Yossey-Bass.

Haris, A. (2002). School improvement. New York \& London: Rouledge Taylor\&Francis Group.

Hasbullah, J. (2006), Social capital (Menuju keunggulan budaya manusia Indonesia).Jakarta: MR-United Press.

Hassim, Andreas (2016). Revolusi Industri 4.0 .| Jumat, 17 Juni 2016 | 7:14.http://id.beritasatu.com/home/revolusi-industri-40/145390.

Hauberer, J.( 2011). Social capital theory. VS Research.

Henderson, N. (2003). Resiliency in schools. California: Corwin Press. Inc.

Henderson, N., \&Milstein, M. M.(2003). Resiliency in schools: Making it happen for students and educators.California : Corwin Press.

Hurn, Cristopher. J. (1993). The limit and possibilities of Schooling. Encycloedia Britania

Kasali, Rhenald. (2017). Disruption. Jakarta : PT Gramedia.

Lunnerburg, F. (2000). Educational administration. USA: Wadsworth.

Nasution, S. M. (2011).Resiliensi: Daya pegas menghadapi trauma kehidupan. Medan: USU Press. 
$\mathrm{Ng}$, P. T. (2017). Learning from the power of paradoxes. New York\&London: Rouledge Taylor\&Francis Group.

Panth, Brajesh (2017). dalam The Policy Brief. Improving education quality and outcomes for national development and development in the $21^{\text {st }}$ Century. The HEAD Foundation. November 2017. Special Issue.

Prayitno. (2009). Dasar teori dan praksis pendidikan. Jakarta: Grasindo.

Ritzer, G. (2012). Teori sosiologi. Yogyakarta: Pustaka Pelajar.

Rosyada, D. (2017). Menjadi guru di Abad 21. Diunduh darihttp://www.uinjkt.ac.id/id/menjadi-guru-di-abad-21/.

Saripudin, D. (2018). Pembangunan pendidikan dan pertumbuhan ekonomi Indonesia. Diunduh dari https://www.researchgate.net/publication/264845858.

Shiwaku, K., Ueda, Y., Oikawa, Y.,\& Shaw, R. (2016).School disaster resilience assessment in the affected areas of 2011 East Japan earthquake and tsunami. Natural Hazards, 82(1), 333-365. doi: 10.1007/s11069-016-2204-5.

Sirozi, M. (2005). Agenda strategis pendidikan Islam. Yogyakarta: AK Group.

Siswoyo, D. (2017). Sekolah dan guru: Dalam tantangan zaman. Yogyakarta: UNY Press.

Soemarno. (2003, 5-6 Agustus). Fondasi penelitian kualitatif dan kuantitatif. Materi Sarasehan Metodologi Pascasarjana UNY.

Suharjo (2014). Peranan modal sosial dalam perbaikan mutu sekolah dasar di Kota Malang(Disertasi). Progam Pascasarjana Universitas Negeri Yogyakarta, Yogyakarta.

Suyata. (2004). Decentralized basic education project, district capacitybuilding. Departemen Pendidikan Nasional Pendidikan Lanjutan Pertama.

Tilaar, H.A.R (2009). Membenahi Pendidikan Nasional, Jakarta: Rineka Cipta.

Tilaar, H.A.R. (2003). Kekuasaan dan pendidikan: Suatu tinjauan dari perspektif studi kultural. Magelang: INDONESIATERA.

Walker, T. D. (2017). Teach like Finland. London: W.W. Norton @ Company Inc.

Yoga, Djohan (2017). Membangun budaya inovasi di perguruan tinggi.Materidisampaikan 8 Februari 2017 padaStadium General UNY..

Yoga, Djohan (2018). Learning HOW to Learn, Materi TOT disampaikan 7-9 April Rektorat UNY.

Zamroni. (2009). Modelmutu pendidikan: Profesionalitas terpadu.Dalam Prosiding Seminar Nasional, Paradigma Mutu Pendidikan di Indoensia. Lembaga Penelitian UNY, Yogyakarta.

Zamroni. (2017). Pendidikan multikultural sebagai upaya untuk mengurangi ketimpangan prestasi. Yogyakarta: UNY. 